\title{
Analysis of Energy Consumption Scenarios of Building in Guangzhou in a Mid-Long Term
}

\author{
Lan Tang, Xiaoqing Zhou, Xin Yang \\ The Institute of Building Energy Conservation, Guangzhou University, Guangzhou, China \\ Email: tanglan@gzhu.edu.cn
}

Received January 2014

\begin{abstract}
According to the year of 2009, calculated energy consumption quantity and energy consumption structure of building in Guangzhou to 2030, analyzed adjustment and approach of sustainable development and potential of energy conservation which can provide commendable technology progress in every department.
\end{abstract}

\section{Keywords}

Calculated; Analyze; Adjustment; Approach; Technology Progress

\section{The Analysis of Basic Situation of Energy Consumption of Building in Guangzhou}

As it investigates tertiary industry and living energy consumption took up 44\% in whole energy consumption in 2009 which mainly take place in building and transportation, so it is significant to analyze and research building energy consumption for energy conservation. According to different function, buildings can be divided into residence buildings, public buildings and industry buildings. Energy consumption of residence buildings included heating, lighting, electrical equipment, air conditioning and cooking. Energy consumption of public buildings included air conditioning, lighting, elevator, office equipment, waterbowl and auxiliary equipments. The analysis of building energy consumption in Guangzhou will not need to consider the heating energy consumption, the energy consumption of residence buildings and public buildings are not expressly listed in the Statistical Yearbook, therefore, this issue will be integrated the energy consumption of energy balance, as the analysis of energy consumption of residence buildings, the third industrial energy (excluding transport, storage and postal industry energy use) as a public building energy analysis [1].

Table 1 shows the energy consumption of buildings from 2001 to 2009 in Guangzhou City, the average annual growth rate was $13.35 \%$, it was significantly higher than the total energy consumption growth rate, this also makes the proportion of energy consumption of buildings taking up total energy consumption increases every year, energy consumption of buildings reached 14.09 million tons of standard coal in 2009 reached $25.22 \%$ of total energy consumption. The public buildings accounted for $60 \%$ in the composition of energy consumption of 
Table 1. The situation of building energy consumption (million tce).

\begin{tabular}{cccccc}
\hline & 2001 & 2003 & 2005 & 2007 & 2009 \\
\hline Residence & 208.17 & 243.59 & 354.35 & 434.81 & 491.25 \\
Public & $44.1 \%$ & $40.1 \%$ & $40.1 \%$ & $36.9 \%$ & $34.9 \%$ \\
Total & 264.43 & 363.89 & 529.54 & 742.87 & 917.9 \\
Proportion (\%) & $56.0 \%$ & $59.9 \%$ & $59.9 \%$ & $63.1 \%$ & $65.1 \%$ \\
\hline
\end{tabular}

buildings, and its average annual growth rate (17.29\%) is higher than the annual growth rate (8.48\%) in residence buildings, therefore, energy conservation of public buildings is an important part of energy conservation of buildings in Guangzhou City.

\section{The Method of Analysis of Energy Demand and Development of Building Field in Guangzhou City}

When we analyze the future development of building energy consumption, we use the scenario analysis method and the modeling tools. Prediction of building energy consumption chooses the "Chinese building energy consumption model” which was developed by Tsinghua University to calculate [2]. Chinese building energy consumption model which calculates the number bottom-up through the intension and quantity of energy consumption, and verified by the statistics macroscopic. It takes climate, economic development, technology and lifestyle factors into account on building energy consumption, classified energy consumption of buildings into tree structure. The results are divided into power consumption and fuel consumption (converted into heat by low standard coal).

The formula is: heating energy consumption (abbreviated).

Residence energy consumption and public buildings energy consumption calculation:

$$
E b=\sum_{n} \sum_{m} \sum_{m} e_{n, m, l} \cdot A b_{n, m, l}
$$

In this formula, $e$ stands the end use of residential energy consumption per unit area/different types of public buildings total energy consumption, unit $\mathrm{kwh} / \mathrm{m}^{2}$, or $\mathrm{kgce} / \mathrm{m}^{2}$; $A b$ stands the corresponding building area, $l$ stands a variety of lifestyles Ratio, $m$ represents a different end-use residential/public buildings type, $n$ represents the climate zone.

In order to reflect the situation of the real causal interaction between a variety of conditions objectively, when we do the scenario analysis, it is necessary to review and evaluate the events that have happened, then analyze the internal relations and regulations, and find out some important factors in it, and assume factors that are uncertain and certain which can affect the development trends reasonably, then reaching the future development trends. These assumptions should be able to match each other, with technical, economic, social and other aspects rationality. As the premise, in respect of model structure, it's an important part to set a reasonable scenario for the issue. Scenarios mainly describe the macro-social development of Guangzhou, as well as the characteristics of building energy consumption to the scene settings. Usually design a basic scenario (BAU, business as usually, that at current trends), and then set some alternative scenarios by changing the assumptions, and then compared with the basic scenario, to study changes in future energy demand. Generally assumed that the future projections of catastrophic events will not occur, because it is difficult to predict such events.

\section{The Analysis of Predict of Energy Demand and Energy Saving Potential in Building Field}

The forecast of building energy consumption scenarios based on relative forecasts of the city's demographic, economic and social development. One aspect, urban population growth makes the urban construction area increases; urban economic development and the improvement of people's living standards bring on the number and variety of energy-using equipment level of service demand. Another aspect, in recent years, Chinese gov- 
ernment attaches great importance to building energy conservation, and correspondingly introduces a number of laws and regulations, standards, policies, measures and economic incentives. Building energy consumption contributes to the future development of the scenario analysis to explore and determine future energy strategy.

\subsection{The Scenarios Setting}

Building energy consumption is decided by total building area and quantity of energy consumption per unit area. Therefore, the main factors that cause building energy consumption changing can be summarized as follows:

1) Changes in the total area building

In addition to the increase in population, the growth of per capita living area also contributed to the growth of total construction area. From 2000 to 2009, total construction area increased 31.29\% in Guangzhou City, urban public building area increased $24.51 \%$, urban residential construction area increased $20.32 \%$, rural residential land area increased 51.55\%. Living space per capita has also increased, urban per capita average annual growth rate of residential area is 2.72\% from 2005 to 2009; 2009 reached 21.01 square meters; average annual growth rate of rural residents per capita residential area is $3.31 \%$, and it reached 40.59 square meters in 2009, public buildings per capita has also increased. The housing area per capita and per capita area of public buildings are at a high level in Guangzhou City, and maintain steady growth. Setting the following two scenarios for the future development trend of per capita area of structure, one is sustainable developing at the current level, the other is strongly controlled by the tax system and the per capita housing area and per capita area of growth in public buildings.

2) Changes in lifestyle

More and more people gradually change the traditional way of building energy consumption, resulting energy consumption raised. Another aspect, the expansion of the concept of lifestyle and consumption has also led to the increase of proportion of new public buildings which are high energy consumption. Setting changes in lifestyle in whole society in scenario analysis, the system of residential and public buildings in the quantification of different groups in the proportion of changes in energy intensity, that is part of the former are "low energy" group of residential and public buildings change lives way for "high energy" group, and "low energy" groups to "medium energy" conversion.

3) The improvement of technical level

Building energy consumption intensity is decided by the number of construction services and building energy efficiency. The level of technology is mainly reflected in: reduce air conditioning load through the building envelope by different local conditions; reduce energy consumption intensity through using efficient energy-saving lamps, air conditioning and electrical equipment. As is investigated the building energy consumption per unit area in 2015 is 1.1 times in 2009, 2020 is 1.3 times for 2009, 2030 is 1.5 times for 2009; when the skill levels of electrical equipment technology greatly increase, the growth of energy-using equipment in building will be offset, energy consumption per unit area remained basically unchanged by 2030 .

Based on the above assumptions of three main factors, we analyze the building energy consumption in 2015, 2020, 2030 by four steps. First, in accordance with current trends of the development of building energy consumption, three factors are all non-energy savings, gaining the scenarios of non-energy savings (baseline scenario); Second, considering energy-saving scenarios of three factors affecting independently; then considering energy-saving scenarios of two of the three factors interact; eventually considering all three aspects of building energy conservation play a great role, that is the most energy-saving scenarios.

\subsection{Model Checking}

From the model, the demand of total building energy consumption in 2009 is 14.414 million tons of standard coal, it is in accordance with the total 14,091,500 tons of standard coal in statistical data and the error does not exceed 2.2\%. The calculation value of residential buildings power consumption is 6.955 billion kw.h in 2009, urban residential electricity consumption in 2009 is 7.399 billion kw.h; rural residential building energy consumption calculation value is 3.71 billion kw.h, rural residential electricity consumption in 2009 is 3.715 billion $\mathrm{kw} . \mathrm{h}$; the calculation value of public buildings power consumption is 11.907 billion kw.h, the value is 11.985 billion kw.h in Statistics, the error of calculation is in the acceptable range. It can be considered that the setting of basic parameters of the model is reasonable, it is credible that the composition and demand of future energy consumption which using the model to calculate. 


\subsection{Energy Demand}

Based on model calculations, if energy-saving measures are weak, according to current trends, Chinese traditional frugal energy consumption and living styles convert gradually to the pattern of perfect service and comfortable environment, and building energy consumption may grow significantly, reaching 59,294,500 tons of coal equivalents by 2030, as shown in Table 2. Energy consumption is almost 4.1 times in 2009 .

Figure 1 shows the situation of building energy consumption in different scenarios in 2030, from the view of reduction of energy consumption, the technology has greatly improved do the most effect to reduction of energy consumption, in the scenario, 2030 energy consumption is only 39,529,700 tons standard coal, save more than $10,953,100$ tons of standard coal than reference scenario, followed by the control of increase of living space per capita, it can save 14,184,800 tons of coal equivalent, it can save 6,407,900 tons of coal equivalent that most people maintain the traditional way of life situations. Improvement of the technical level can offset the increase in floor area and using equipment that due to increase in building energy consumption per unit area, it must rely on existing technology and breakthrough innovation, it is difficult. Control the living space per capita and maintaining the existing traditional way of life for most people also requires government's strong guidance and the people's cooperation.

Of course, the two factors of three factors working together can make reduction of energy consumption more significant, when the floor space per capita has been effectively controlled, most people remain the harmonious way of life at current, and the technology improved, the advanced technologies can be effectively promoted, energy consumption is only 30,390,400 tons of standard coal in the best energy scenario in 2030, it is only 51\% of energy consumption in the baseline scenario in 2030, saving nearly $49 \%$ of energy.

The composition of the total energy consumption in the baseline scenario in 2030 is shown in Figure 2, it is obvious that A: non-electric energy consumption and B: power consumption is the most important part of the total building energy consumption in public buildings, they were $50 \%$ and $9 \%$, a total of $59 \%$; urban residential electric energy consumption $\mathrm{F}$ and urban residential non-electric energy consumption $\mathrm{E}$ is $31 \%$, followed by rural residential electric energy consumption $\mathrm{D}$ and rural residential non-electric energy consumption $\mathrm{C}$, only $10 \%$.

\section{Conclusion}

In this paper, we used the method of scenario analysis, combined with the corresponding model, analyzed the energy development scenarios of construction and transportation sector in Guangzhou, making 2009 year as the base year, under certain assumptions, predicted the energy consumption and structure in construction sector to 2030, it will be able to provide good ideas and evidence to choose adjustment of energy structure and technological progress.

Table 2. Table of building energy demand (million tons of standard coal/year).

\begin{tabular}{ccccc}
\hline Scenarios & 2009 & 2015 & 2020 & 2030 \\
\hline Baseline scenario & 1441.40 & 2126.99 & 3234.90 & 5929.45 \\
Low-floor area & 1441.40 & 2014.97 & 2847.97 & 5288.66 \\
$\begin{array}{c}\text { To maintain the traditional way of life } \\
\text { Technology has greatly improved }\end{array}$ & 1441.40 & 2045.11 & 2996.48 & 3952.97 \\
$\begin{array}{c}\text { Low-floor area + to maintain the } \\
\text { traditional way of life }\end{array}$ & 1441.40 & 1933.63 & 2488.39 & 4019.91 \\
$\begin{array}{c}\text { Low floor space + technology has } \\
\text { greatly improved }\end{array}$ & 1441.40 & 1937.39 & 2638.06 & 3212.76 \\
$\begin{array}{c}\text { To maintain the traditional way of life } \\
+ \text { technology has greatly improved } \\
\text { Best scenario }\end{array}$ & 1441.40 & 2037.80 & 2387.80 & 3998.25 \\
\hline
\end{tabular}




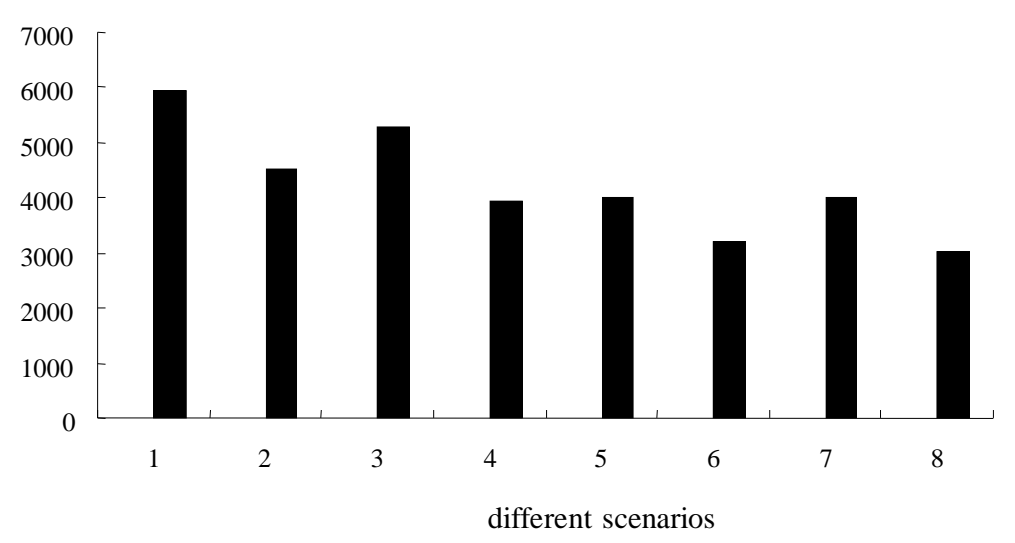

Figure 1. Energy consumption in different scenarios.

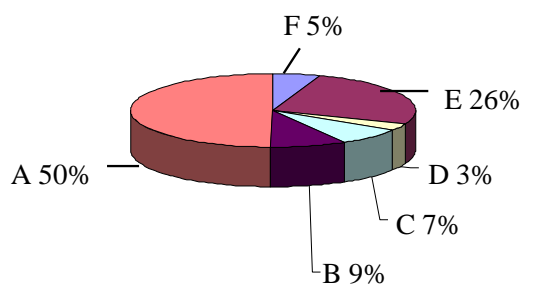

Figure 2. The composition of total energy consumption in the baseline scenario in 2030.

\section{Acknowledgements}

We thank the support from the National Natural Science Foundation of China (51078092) and "Yangcheng scholar” project of Education Bureau of Guangzhou (10A039G).

\section{References}

[1] Statistical Yearbook of Guangzhou. China Statistics Press.

[2] (2009) China Building 2009 Annual Report on Energy. Building Energy Research Center of Tsinghua University, China Building Industry Press, Beijing. 